AperTO - Archivio Istituzionale Open Access dell'Università di Torino

\title{
Comparative external validation of the PRECISE-DAPT and PARIS risk scores in 4424 acute coronary syndrome patients treated with prasugrel or ticagrelor
}

\section{This is the author's manuscript}

Original Citation:

Availability:

This version is available http://hdl.handle.net/2318/1721549

since 2020-01-06T23:39:43Z

Published version:

DOI:10.1016/j.ijcard.2019.11.132

Terms of use:

Open Access

Anyone can freely access the full text of works made available as "Open Access". Works made available under a Creative Commons license can be used according to the terms and conditions of said license. Use of all other works requires consent of the right holder (author or publisher) if not exempted from copyright protection by the applicable law. 


\section{Comparative external validation of the PRECISE-DAPT and PARIS risk scores in 4,424 acute coronary syndrome patients treated with prasugrel or ticagrelor.}

Matteo Bianco ${ }^{1} \mathrm{MD}$; Fabrizio D'ascenzo ${ }^{* 2} \mathrm{MD}$; Sergio Raposeiras Roubin ${ }^{* 3} \mathrm{MD}, \mathrm{PhD}$; Tim Kinnaird ${ }^{4}$ MD; Mattia Peyracchia² MD; Albert Ariza-Solé ${ }^{5}$ MD, PhD; Enrico Cerrato6MD; Sergio ManzanoFernández $z^{7}$; Carol Gravinese ${ }^{1}$ MD; Christian Templin ${ }^{8}$ MD, PhD; Paola Destefanis ${ }^{1}$ MD, Lazar Velicki ${ }^{9}$ MD; Alessia Luciano ${ }^{1}$ MD; loanna Xanthopoulou ${ }^{10}$ MD, PhD; Mauro Rinaldi11 MD, Prof; Andrea Rognoni ${ }^{12}$ MD; Ferdinando Varbella ${ }^{6}$ MD; Giacomo Boccuzzi $i^{13}$ MD; Pierluigi Omedè2 MD; Andrea Montabone ${ }^{13} \mathrm{MD}$; Alessandro Bernardi ${ }^{2} \mathrm{MD}$; Salma Taha ${ }^{14} \mathrm{MD}$; Roberta Rossini ${ }^{15} \mathrm{MD}$, $\mathrm{PhD}$; Alessandro Durante ${ }^{16} \mathrm{MD}$; Sebastiano Gili ${ }^{8} \mathrm{MD}$; Giulia Magnani ${ }^{8} \mathrm{MD}$, PhD; Michele Autelli ${ }^{2}$ MD; Alberto Grosso 2 MD; Pedro Flores Blanco ${ }^{5}$ MD; Carla Giustetto ${ }^{2}$ MD, Prof; Alberto Garay ${ }^{7}$ MD; Giorgio Quadri6 MD; , Berenice Caneiro Queija ${ }^{3}$ MD; Ilija Srdanovic ${ }^{9}$ MD; Rafael Cobas Paz ${ }^{3}$ MD; María Cespón Fernández ${ }^{3}$ MD; Isabel Muñoz Pousa ${ }^{3}$ MD; Diego Gallo ${ }^{17}$ Eng, PhD; Umberto Morbiducci ${ }^{17}$ Eng, Prof; Alberto Dominguez-Rodriguez ${ }^{18}$ MD, Prof; Ángel Lopez-Cuenca ${ }^{7}$ MD; Angel Cequier ${ }^{5} \mathrm{MD}$; Dimitrios Alexopoulos ${ }^{10} \mathrm{MD}$, Prof; Andres Iñiguez-Romo ${ }^{3} \mathrm{MD}$; Roberto Pozzi ${ }^{1}$ MD; Emad Abu Assi**3 MD, PhD; Marco Valgimigli**19 MD, Prof.

1) Division of Cardiology, San Luigi Gonzaga University Hospital, Orbassano, Italy, 2) University of Turin, 'Città della Salute e della Scienza di Torino', Division of Cardiology, Turin, Italy, 3) Department of Cardiology, Hospital Álvaro Cunqueiro, Vigo, Pontevedra, Spain, 4) Cardiology Department, University Hospital of Wales, Cardiff, United Kingdom,5) Department of Cardiology, University Hospital de Bellvitge, Barcelona, Spain, 6) Interventional Cardiology Unit, San Luigi Gonzaga University Hospital, Orbassano and Infermi Hospital, Rivoli, Turin, Italy, 7) Department of Cardiology, University Hospital Virgen Arrtixaca, Murcia, Spain, 8) Department of Cardiology, University Heart Center, University Hospital Zurich, Switzerland, 9) Medical faculty, University of Novi Sad, Novi Sad, Serbia and Institute of cardiovascular Diseases Vojvodina, Sremska Kamenica, Serbia, 10) University Patras Hospital, Athens, Greece, 11) University of Turin, 'Città della Salute e della Scienza di Torino', Division of Cardiac Surgery, Turin, Italy, 12) Catheterization Laboratory, Maggiore della Carità Hospital, Novara, Italy, 13) Department of Cardiology, S.G. Bosco Hospital, Torino, Italy, 14) Department of Cardiology, Faculty of Medicine, Assiut University, 15) Division of Cardiology, A.O Santa Croce e Carle, Cuneo, Italy, 16) U.O. Cardiologia, Ospedale Valduce, Como, Italy, 17) PolitoBIOMed Lab, Department of Mechanical and Aerospace Engineering, Politecnico di Torino, 18) Department of Cardiology, University Hospital from Canarias, Tenerife, Spain, 19) Swiss Cardiovascular Center Bern, Bern University Hospital, Switzerland

*joint second authorship

** joint last authorship

Correspondence to: Dr. Matteo Bianco, MD, Division of Cardiology, San Luigi Gonzaga University Hospital, Orbassano, Italy. E-mail: matteo.bianco87@gmail.com; www.cardiogroup.org. 


\begin{abstract}
Background. The PRECISE-DAPT and PARIS risk scores (RSs) were recently developed to help clinicians at individualizing the optimal dual antiplatelet therapy duration (DAPT) after percutaneous coronary intervention (PCI). Nevertheless, external validation of these RSs it has not yet been performed in ACS (acute coronary syndrome) patients treated with prasugrel or ticagrelor in a real- world scenario.
\end{abstract}

Methods: 4,424 ACS patients who underwent $\mathrm{PCl}$ and survived to hospital discharge, from January 2012 to December 2016 at 12 European centers, were included. PRECISE-DAPT and PARIS bleeding RS, as well as PARIS ischemic RS, were computed, and their performance at predicting major bleeding (MB; BARC type 3 or 5 ) and ischemic events ( $\mathrm{Ml}$ and stent thrombosis) during follow up was compared.

Results: After a median follow-up of 14 (interquartile range 12-20.9) months, $83(1.88 \%)$ patients developed MB and 133 (3.0\%) suffered an ischemic episode. PRECISE-DAPT performed better than PARIS bleeding RS (c-statistic= 0.653 vs. $0.593 ; p=0.01$ for comparison) in predicting $M B$. The RSs performance for MB prediction remained consistent in STEMI patients (c-statistic $=0.632$ vs 0.575 ) or in those treated with prasugrel (c-statistic $=0.623$ vs 0.586 ).

PARIS ischemic RS exhibited modest but superior discrimination in predicting ischemic complications as compared to PRECISE-DAPT (c-statistic= 0.604 vs $0.568 p=0.05$ for comparison).

Conclusion: Our data provide support to the use of PRECISE-DAPT in MB risk stratification for patients receiving DAPT in form of aspirin and prasugrel or ticagrelor whereas the PARIS ischemic RS has potential to complement the risk prediction with respect to ischemic events.

Keywords: DAPT, prasugrel, ticagrelor, bleeding; PRECISE DAPT; PARIS risk score 


\section{INTRODUCTION}

Dual antiplatelet therapy (DAPT), consisting of aspirin and a P2Y12 inhibitor (P2Y12i) is the standard of care in patients treated with percutaneous coronary intervention $(\mathrm{PCl})$ and stent implantation. Yet, the most appropriate DAPT duration, especially in patients at high bleeding risk with prior acute coronary syndrome (ACS) remains a subject of intense controversy.

The originally proposed "one-fits-all" strategy based on an at least twelve months regimen of DAPT has been questioned and a tailored treatment duration informed by the individual ischemic and bleeding risks has been more recently advocated ${ }^{1-4}$.

The PRECISE-DAPT and PARIS risk scores (RSs) have been recently developed to help physicians in stratifying post-discharge bleeding and ischemic risk in patients treated with DAPT after $\mathrm{PCl}^{5,6}$. Although both scores demonstrated a moderate predictive ability, the European Society of Cardiology (ESC) DAPT focused update exclusively endorsed, with a class Ilb recommendation, the use of PRECISE-DAPT score, in view of a gap in knowledge whether PARIS RS improves the decision making on DAPT duration.

However, the recommendation of the ESC regarding the use of PRECISE-DAPT is based on a single study where patients were largely treated with aspirin and clopidogrel ${ }^{5}$. Therefore, further investigating the predictive capability and reliability of PRECISE-DAPT seems necessary before generalizing its use to other populations with different clinical features, health systems and more contemporary medications. In addition, PRECISE-DAPT was derived from clinical trial patients, at variance with the PARIS RSs, which was developed from registry patients.

We sought to evaluate and compare the external validity of PRECISE-DAPT and PARIS RSs in contemporary real-world ACS patients treated with aspirin and prasugrel or ticagrelor. 


\section{METHODS}

\section{Study Population}

The design and patient population of RENAMI (REegistry of New Antiplatelet therapy in Myocardial Infarction) was comprehensively described elsewhere ${ }^{7}$. Briefly, in RENAMI dataset, consecutive ACS patients recruited at 12 European centers from January 2012 to December 2016 were included (supplementary appendix). The RENAMI registry included all comer patients with a final diagnosis of ACS: unstable angina (UA), non ST-segment elevation myocardial infarction (NSTEMI), or ST-segment elevation myocardial infarction (STEMI), aged at least 18 years, who consented for participation in the study. All patients underwent in-hospital coronary angiography and $\mathrm{PCl}$ with stent implantation followed by aspirin and either ticagrelor or prasugrel, at discretion of the treating physician. All patients were discharged with DAPT (aspirin plus ticagrelor or aspirin plus prasugrel). Excluded patients from the present analysis were those who experienced any adverse event defined as major bleeding (MB), new MI, stent thrombosis (ST), cardiovascular death or death for any causes during the index hospitalization. The institutional review board of each center approved the study protocol.

\section{Objectives}

We sought to evaluate and compare the performance of PRECISE-DAPT and PARIS RSs at predicting post-discharge $\mathrm{MB}$ and ischemic events (MI and ST), in the overall cohort and in subgroups of interest, including STEMI vs. NSTEACS (UA and NSTEMI), ticagrelor vs. prasugrel, and according to different DAPT durations ( $<12$ months, 12 months, and $>12$ months).

\section{Follow-up and definitions}

The follow-up was conducted at each single center with at least two in contact visits within the first year after inclusion in order to assess the occurrence of any relevant clinical events and assess drug-adherence. Data on vital status (alive or dead) and events during follow-up were obtained from hospital clinical data records, as well as from administrative records (vital statistics registers, hospital discharge data and emergency department data), and telephone contact was 
made with patients or their relatives and primary care physicians in particular cases for which information was not available.

Follow-up time was ended by DAPT duration; therefore, the events recorded (MB or MI/ST or cardiovascular death) occurred while patients were on DAPT. We only considered the first MB or MI/ST episodes occurred during follow-up. Therefore, in patients who had developed more than one complication, the follow-up time was ended at the time of the first of the prior complications.

Major bleeding was defined as those fulfilling type 3 or type 5 BARC criteria ${ }^{8}$. Ischemic events were defined as a composite of new Ml or stent thrombosis or cardiovascular death. A new MI was defined according to the third definition of myocardial infraction ${ }^{9}$. ST was defined according to Academic Research Consortium criteria ${ }^{10}$. Cardiovascular death includes deaths that result from an $\mathrm{MI}$, sudden cardiac death, death due to heart failure, death due to stroke, death due to cardiovascular procedures.

\section{Risk scores calculation}

PRECISE-DAPT and PARIS were calculated in each patient on the basis of the original definitions used in their development cohorts (Supplementary Table 1-2, Supplementary Figure

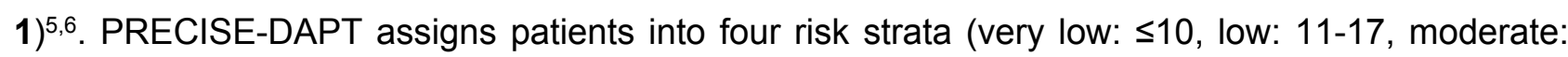
18-24, and high: $\geq 25$ points), whereas PARIS bleeding risk score categorizes patients into three risk groups (low: $<3$, moderate: $3-7$, and high: $\geq 8$ points). PARIS ischemic risk score also categorized patients into three strata but with different cut points: low: $<2$; intermediate: $3-4$ : and high: $\geq 5$ points.

To enable comparisons between the PRECISE-DAPT and PARIS risk classification systems we categorized all patients into three risk strata by considering the very low and low risk categories in PRECISE-DAPT as a unique category. 


\section{Data presentation and statistical analysis}

Baseline and clinical characteristics of the RENAMI external validation population, and the derivation cohorts of the PRECISE- DAPT and PARIS scores are presented as mean \pm standard deviation (SD) and medians (interquartile ranges [IQR]) for continuous variables, and as proportions for categorical variables.

The total RSs, as continuous variables, were entered into separate Cox regression models to test their association with ischemic and MB events. The ability to separate high-risk from lower risk patients was visually appraised by generation of Kaplan-Meier curves for events of interest and compared using the log-rank test. The magnitude of the association between each of the three predefined risk categories from the RSs was calculated and expressed as hazard ratios $(\mathrm{HR})$ with their $95 \%$ confidence intervals $(95 \% \mathrm{Cl})$; the low risk category was considered as a reference category.

The predictive capacity of the RSs was tested by means of indices of discrimination and calibration. To assess discrimination, using the total RS as a global prognostic indicator, we calculated and compared the Harrell c-statistic for censored time-to-event data, for both scores ${ }^{11}$. Calibration was computed using the Grønnesby and Borgan $\mathrm{X}^{2}$ test, and plotted observed vs. predicted outcomes.

The time-frame of 12 months was used to assess the ability of both scores to predict outcomes over the first year, in order to decide to stop or to prolong DAPT. The Kaplan-Meier curves end at 18 months in order to show the whole study follow-up.

We further assessed the net reclassification improvement index $(\mathrm{NRI})^{12}$. For the NRI calculation, individuals were compared based on their bleeding and ischemic risk using the three categories of the two RSs. Since the probability of MB and MI/ST was set at different thresholds in the respective risk categories of PRECISE-DAPT and PARIS, we further analyzed possible improvement in the discrimination ability of one score vs. the other by means of the "categoryless" NRI. Although there are no established benchmarks for category-free NRI (cfNRI), Pencina et al. 


\section{RESULTS}

\section{Baseline characteristics}

The baseline characteristics of the RENAMI population are summarized in table 1. Patients in RENAMI were younger and less frequently females, as compared with those used to generate the the PRECISE-DAPT and PARIS RSs.

Most of patients in this study had STEMI and largely received drug eluting stent implantation. All patients received DAPT in form of either prasugrel or ticagrelor. A total of $22.3 \%, 50.1 \%$ and $27.6 \%$ of the patients in the RENAMI study received DAPT for less then 12 months, 12 months or more than 12 months, respectively. 
The PRECISE-DAPT varied from 0 to 75 points ( $17 \pm 10$ points), and $20.4 \%$ of patients were categorized as having high risk of bleeding. (Figure 1). In contrast, the PARIS bleeding RS values ranged from 0 to 10 points ( $3 \pm 2$ points), with only $3.9 \%$ of patients fulfilling the high-risk category (Figure 1).

The PARIS ischemic score ranged from 1 to 13 points ( $4 \pm 2$ points) with $23.1 \%$ of the patients being categorized at high ischemic risk.

\section{Bleeding and ischemic risk assessment based on the RSs classification systems}

After a median follow-up of 14 (IQR: 12-20.9) months, 83 (1.88\%) patients developed MB and $133(3.0 \%)$ suffered an ischemic episode. Median time for first MB was 5.0 (IQR 1.6-9.4) months, and for ischemic events 9.6 (IQR 2.6-16.9) months. The Kaplan-Meier curves based on risk categories assigned by each score for the occurrence of MB are shown in Supplementary Figure 2. Both PRECISE-DAPT and PARIS bleeding RSs showed significant predictive capability (log-rank test, $p<0.01)$. The observed bleeding rates for the two scores increased monotonically from low- to high-risk categories. However, Kaplan-Meier curves diverged in a more pronounced way with PRECISE-DAPT ( $x^{2}$ values were 23 [ $p<0.001$ ] for PRECISE-DAPT vs. 10 [ $p=0.002$ ] for PARIS). After an adjustment for potential clinically relevant confounders (age, sex, hypertension, diabetes mellitus, history of malignancies, prior-MI, prior-bleeding, anemia, creatinine clearance, ACS or non-ACS clinical presentation, DES or BMS, enrolling center), with Cox regression models both PRECISE DAPT and PARIS bleeding RSs confirmed their independent ability to predict MBs on the basis of their risk categories (PRECISE DAPT moderate risk HR: $2.56 \mathrm{Cl}: 1.52-4.31 \mathrm{p}<$ 0.0001; PRECISE DAPT high risk HR: $4.01 \mathrm{Cl}: 2.57-6.28 p<0.0001$ and PARIS bleeding moderate risk HR: $2.11 \mathrm{Cl}: 1.39-3.21 \mathrm{p}<0.0001$; PARIS bleeding high risk HR: $5.78 \mathrm{Cl}: 3.16$ $10.55 p<0.0001)$. Similar results were observed for the prediction of ischemic events (PRECISE DAPT moderate risk HR: $2.33 \mathrm{Cl}: 1.34-4.08 \mathrm{p}=0.003$; PRECISE DAPT high risk HR: $3.07 \mathrm{Cl}$ : 
$1.88-5.04 p<0.0001$ and PARIS ischemic moderate risk HR: $2.00 \mathrm{Cl}: 1.31-3.07 \mathrm{p}=0.001$; PARIS ischemic high risk $2.60 \mathrm{Cl}: 1.68-4.02 \mathrm{p}<0.0001)$.

Consistent findings were noted for the predictive value of both RSs in predicting MI/ST or cardiovascular death (supplementary materials Figure 3-4)

\section{Discrimination}

Both PRECISE-DAPT and PARIS bleeding scores, as continuous variables, were better than the chance for predicting MB. However, the PRECISE-DAPT performed better than the PARIS bleeding RS at c-statistics (c-statistic= 0.653, [95\% Cl: 0.59-0.71]; c-statistic: $0.593,[95 \% \mathrm{Cl}$ : 0.528-0.658]; $p=0.01$ for correlated c-statistic values comparison).

In contrast, the discriminative capacity of PARIS ischemic RS, as compared to PRECISE-DAPT, was slightly higher $(\mathrm{c}-$ statistic $=0.604,[95 \% \mathrm{Cl}: \quad 0.550-0.657]$ and $0.568[95 \% \mathrm{Cl}: 0.509-0.626]$; $\mathrm{p}=0.05$ for correlated c-statistics values comparison).

The c-statistic values for different DAPT duration, clinical presentation, P2Y12 inhibitors, age and serum creatinine level are summarized in table 2. Briefly, the PRECISE-DAPT score was able to predict MB reasonably well and better than the PARIS bleeding RS in almost all analyzed sub-categories but its discriminative capacity for $M B$ was found to be slightly reduced in patients treated with prasugrel, patients $>75$ years and in patients with STEMI at presentation compared to those treated with ticagrelor, patients $<75$ years and those with NSTEACS at presentation. Finally, PARIS ischemic RS was better than PRECISE DAPT in predicting ischemic events in all subgroup analyses with the exception of patients treated with ticagrelor in which the discrimination performance of the scores is almost the same.

\section{Calibration}

Calibration of observed against predicted MB was good for both RSs, although PRECISE DAPT slightly tended to underestimate the predicted probability of MB compared to PARIS 
bleeding RS. The calibration of PRECISE DAPT for observed against predicted ischemic events was suboptimal if compared with PARIS ischemic risk score as shown in Supplementary figure 5. In the figure, for each bin, the $y$-value is the proportion of true outcomes, and $x$-value is the mean predicted probability. Therefore, a well-calibrated model has a calibration curve that hugs the straight line $y=x$ (blue line). The red points identify the observed probability of events based on the estimate of the score, so that if they are above the blue line they indicate that the score underestimates, and if they are below the blue line it indicates that the score overestimate.

\section{Average daily rate events}

PRECISE DAPT was able to predict the average daily difference between bleeding and ischemic events better than PARIS risk scores in all the three risk categories in the first year as shown in supplementary materials Figure 6. In particular, the average daily difference of events followed the risk categories stratification for PRECISE DAPT whereas wide overlap between risk categories and observed average daily rate events was noted for the two PARIS risk scores.

\section{Decision curves analyses for MB}

Figure 2 compares the decision curves from classifying individuals using the PRECISE DAPT and PARIS bleeding RSs, assuming all patients will bleed (all positive or all are at high risk of bleeding), and assuming all patients as if none will bleed (all negative or all are at low risk of bleeding; horizontal line at 0 ). The DCA showed that the use of PRECISE DAPT is superior to PARIS bleeding RS at a risk threshold of $\geq 2 \%$. PARIS bleeding RS did not prove to be advantageous, as compared to no use of the score, at a risk threshold of $\geq 3 \%$, whereas PRECISEDAPT RS continued to stratify the bleeding risk until a threshold of $10 \% \mathrm{MB}$ risk. The net benefit analysis for MB is summarized in Supplementary Table 3. The PRECISE DAPT showed superior predictive capability for MB events as opposed to the PARIS bleeding RS with a moderate improvement on risk prediction even when using a category-free $\mathrm{NRI}=0.41(95 \% \mathrm{Cl}$ : 0.20-0.65)

\section{DISCUSSION}

The main findings of this study are: 
1) The PRECISE DAPT and PARIS bleeding RS perform moderately well in predicting MB in patients treated with ticagrelor or prasugrel in the first fourteen months after discharge. 2) PRECISE DAPT is significantly superior to PARIS bleeding RS for predicting MB. 3) The performance of both the RSs is consistent in all the subgroups included in the analysis. 4) PARIS ischemic RS is slightly better than PRECISE DAPT in predicting ischemic events.

There is an emerging need to focus on the trade off between ischemic and bleeding risks when treating contemporary patients with prolonged potent anti-thrombotic medications. in order to maximize the benefit and avoid the risks. The ischemic risk is progressively decreasing in the last years thanks to a great technological improvement of the stents and of $\mathrm{PCl}$ techniques ${ }^{15}$. At the same time, the use of more potent anti-platelets therapies in ACS patients and to the ageing of patients undergoing routine treatment, the bleeding events have become prevalent and they are able to dramatically affect the prognosis of our patients ${ }^{16-19}$.

Costa et al. and Baber et al. generated new models to better predict the incidence of MB and ischemic events in the first 12 or 24 months of treatment respectively, overcoming the limitations of previous studies, which mainly focused on in hospital events. The PRECISE DAPT modeled exclusively the bleeding risk and found that a score $\geq 25$ points may be used in the decision-making of shortening DAPT duration to avoid bleeding. It was validated in patients enrolled in the PLATO study and in the Bern PCl registry (both ACS and stable angina) and showed superiority in the discrimination and reclassification performance respect to the PARIS bleeding RS.

In our study we tested the performance of PRECISE DAPT and PARIS RSs in a real-world registry with characteristics different from the derivation cohorts. First, all our patients were ACS with more than fifty percent of those presenting STEMI and were treated with prasugrel or ticagrelor. Yet, both bleeding RSs demonstrated a reasonable discriminative capacity to predict $\mathrm{MB}$, hence confirming the results of previous studies, which were largely undertaken in patients treated with clopidogre $\left.\right|^{5,6}$. 
We found that PRECISE DAPT was superior to PARIS bleeding RS in predicting MB. Despite similar results in the risk stratification of our population, the discrimination power, the average daily difference between bleeding and ischemic events and net benefit of PRECISE DAPT was superior particularly in the first year of follow-up. These results are consistent with the study of Costa et $\mathrm{al}^{5}$.

A recent study of Abu-Assi et al provided opposite results in terms of performance of the two bleeding RSs considered ${ }^{20}$. This could be due to some differences in the baseline characteristics between the prior study and this cohort. Patients included in the RENAMI study were treated with prasugrel or ticagrelor, while in the study by Abu-Assi et al the majority of patients received clopidogrel; moreover, twenty percent of the patients of Abu-Assi et al were treated with a bare metal stent and data on the DAPT duration was not taken into account ${ }^{20}$. Taken all together, the prior study seems less generalizable to a population treated with the current standard of care and this could explain the different performance of bleeding RSs observed.

Of note, in our study, the use of both bleeding RSs was superior to the strategies of not using the RSs for bleeding risk classification, as observed in the DCA. This means that the use of PRECISE-DAPT and PARIS bleeding RS is of clinical value to drive clinical decisions in bleeding risk stratification. Moreover, our work confirms the previous results from Raposeiras Roubin et al. on the utility of the PARIS RSs but shows that the PRECISE DAPT score is even better. In fact, over a risk score threshold of the $3 \%$ the PARIS bleeding RS failed to demonstrate a benefit over the strategy of not using a RS. For this reason, our observations strengthen the recommendation of the recent ESC position paper on anti-platelet therapy who recommend to use PRECISE DAPT score in bleeding risk stratification ${ }^{1}$.

Due to the great difference in baseline characteristics between RENAMI cohort and the derivation cohorts of the PRECISE DAPT and PARIS RSs, we appraised the accuracy in predicting bleeding and ischemic events in different patient subgroups. We found a modest reduction in the accuracy of predicting MB events of PRECISE DAPT and PARIS bleeding RS in particular among patients treated with prasugrel, in those presenting with STEMI and in those $>75$ years. In this 
three cohorts, the accuracy of both the scores was slightly reduced compared to the general population but overall, as showed in Table 2, the discrimination capacity is consistent in all the subgroups included in the analysis. The reduction in the discrimination ability of PRECISE DAPT score in patients treated with prasugrel was already shown by Costa et al. and is probably related to the average low bleeding profile of patients treated with prasugrel $(<75$ years, $>60 \mathrm{~kg}$ and without previous intracranial bleedings $)^{5}$. Finally, our analysis confirmed that the accuracy of bleeding risk scores decrease in elderly population as already shown in a previous study22.

The ischemic events prediction of PRECISE DAPT score is largely insufficient which is a consistent observation with the fact that this model was purely generated for bleeding prediction purposes.

The current results endorse the implementation of PRECISE DAPT score in the clinical practice as novel tool, particularly within the first year after intervention, to balance the bleeding and ischemic risks as shown by our average daily difference events analysis. The PRECISE-DAPT score allows selecting patients who derive benefit from a short DAPT ( 3 or 6 months) as well as those who should be treated with DAPT as long as possible, which is in keeping with current European guidelines ${ }^{1}$. On the other hand, the use of the PARIS risk scores does not seem to provide clinicians with clear risk stratification information due to some degree of overlap among different risk strata for bleeding and ischemic events.

\section{LIMITATIONS}

This study has several limitations. This was a retrospective observational study, so we cannot rule out the presence of selection bias and unmeasured confounding factors. Moreover, we used treatment at discharge as a principle of intention-to-treat analysis, as we did have data on DAPT duration during follow-up. However, this principle was also applied in the PLATO and Bern PCI external validation cohorts used in the development of the PRECISE-DAPT score, and in the PARIS development cohorts ${ }^{5,6}$. Finally, BARC criteria were used to define bleeding in our study 
and in PARIS, in contrast to PRECISE-DAPT where bleeding definitions were based on TIMI criteria. This point could have affected the comparability of the scores. However, BARC bleeding criteria were also used as an alternative bleeding definition in the external validation cohorts of PRECISE-DAPT. Additionally, BARC bleeding criteria are currently considered the standard bleeding definition. Finally, Costa et al. showed a lower discrimination of PRECISE-DAPT score in patients treated with proton pump inhibitors (PPI); these medications are very important to reduce gastro intestinal bleedings in patients treated with DAPT, unfortunately we did not collect systematically the PPI treatment in our database and we are not able to provide any analysis on the influence of PPI in the performance of the RSs included in the analysis.

\section{CONCLUSION}

Our data provide support to the use of PRECISE-DAPT in MB risk stratification for patients receiving DAPT in form of aspirin and prasugrel or ticagrelor whereas the PARIS ischemic RS has potential to complement the risk prediction with respect to ischemic events.

\section{CONFLICT OF INTERESTS}

Prof. Valgimigli has received research grants to the institution from Terumo, Medicure, Abbott, Astrazeneca and honorarium fees from Abbott, Chiesi, Bayer, Daiichi Sankyo, Amgen, Terumo, Astrazeneca, Alvimedica and Biosensors.

\section{ACKNOWLEDGMENTS}

The authors wish to thank Michael Andrews for his valuable contribution to the English revision. 


\section{Bibliography}

1. Valgimigli $M$, Bueno $H$, Byrne RA, Collet J-P, Costa $F$, Jeppsson A, Jüni $P$, Kastrati $A$, Kolh P, Mauri L, Montalescot G, Neumann F-J, Petricevic M, Roffi M, Steg PG, Windecker S, Zamorano JL, Levine GN, ESC Scientific Document Group, ESC Committee for Practice Guidelines (CPG), ESC National Cardiac Societies. 2017 ESC focused update on dual antiplatelet therapy in coronary artery disease developed in collaboration with EACTS: The Task Force for dual antiplatelet therapy in coronary artery disease of the European Society of Cardiology (ESC) and of the European Association for Cardio-Thoracic Surgery (EACTS). Eur Heart J. 2018;39:213-260.

2. Authors/Task Force members, Windecker S, Kolh P, Alfonso F, Collet J-P, Cremer J, Falk V, Filippatos G, Hamm C, Head SJ, Jüni P, Kappetein AP, Kastrati A, Knuuti J, Landmesser U, Laufer G, Neumann F-J, Richter DJ, Schauerte P, Sousa Uva M, Stefanini GG, Taggart DP, Torracca L, Valgimigli M, Wijns W, Witkowski A. 2014 ESC/EACTS Guidelines on myocardial revascularization: The Task Force on Myocardial Revascularization of the European Society of Cardiology (ESC) and the European Association for Cardio-Thoracic Surgery (EACTS)Developed with the special contribution of the European Association of Percutaneous Cardiovascular Interventions (EAPCI). Eur Heart J. 2014;35:2541-2619.

3. Levine GN, Bates ER, Bittl JA, Brindis RG, Finn SD, Fleisher LA, Granger CB, Lange RA, Mack MJ, Mauri L, Mehran R, Mukherjee D, Newby LK, O'Gara PT, Sabatine MS, Smith PK, Smith SC. 2016 ACC/AHA Guideline Focused Update on Duration of Dual Antiplatelet Therapy in Patients With Coronary Artery Disease: A Report of the American College of Cardiology/American Heart Association Task Force on Clinical Practice Guidelines. J Am Coll Cardiol. 2016;68:10821115.

4. Gravinese C, Bianco M, Cerrato E, Destefanis P, Luciano A, Bernardi A, Bellucca S, Varbella F, Gaita F, Pozzi R. Is Aspirin Still the Cornerstone of Antiplatelet Therapy in Patients With Coronary Artery Disease? An Historical and Practical Narrative Review. Hosp Pract Res. 2017;2:94-101.

5. Costa F, van Klaveren D, James S, Heg D, Räber L, Feres F, Pilgrim T, Hong M-K, Kim HS, Colombo A, Steg PG, Zanchin T, Palmerini T, Wallentin L, Bhatt DL, Stone GW, Windecker S, Steyerberg EW, Valgimigli M, PRECISE-DAPT Study Investigators. Derivation and validation of the predicting bleeding complications in patients undergoing stent implantation and subsequent dual antiplatelet therapy (PRECISE-DAPT) score: a pooled analysis of individual-patient datasets from clinical trials. Lancet Lond Engl. 2017;389:1025-1034.

6. Baber U, Mehran R, Giustino G, Cohen DJ, Henry TD, Sartori S, Ariti C, Litherland C, Dangas G, Gibson CM, Krucoff MW, Moliterno DJ, Kirtane AJ, Stone GW, Colombo A, Chieffo A, Kini AS, Witzenbichler B, Weisz G, Steg PG, Pocock S. Coronary Thrombosis and Major Bleeding After PCI With Drug-Eluting Stents: Risk Scores From PARIS. J Am Coll Cardiol. 2016;67:22242234.

7. Raposeiras-Roubín S, Abu-Assi E, D’Ascenzo F, Fernández-Barbeira S, Kinnaird T, ArizaSolé A, Manzano-Fernández S, Templin C, Velicki L, Xanthopoulou I, Cerrato E, Quadri G, 
Rognoni A, Boccuzzi G, Montabone A, Taha S, Durante A, Gili S, Magnani G, Autelli M, Grosso A, Flores Blanco P, Garay A, Varbella F, Tommassini F, Caneiro Queija B, Cobas Paz R, Cespón Fernández M, Muñoz Pousa I, Gallo D, Morbiducci U, Domínguez-Rodríguez A, Baz-Alonso JA Valdés M, Cequier Á, Gaita F, Alexopoulos D, Íñiguez-Romo A. Annual Incidence of Confirmed Stent Thrombosis and Clinical Predictors in Patients With ACS Treated With Ticagrelor or Prasugrel. Rev Espanola Cardiol Engl Ed. 2019; 72: 298-304.

8. Mehran R, Rao SV, Bhatt DL, Gibson CM, Caixeta A, Eikelboom J, Kaul S, Wiviott SD, Menon V, Nikolsky E, Serebruany V, Valgimigli M, Vranckx P, Taggart D, Sabik JF, Cutlip DE, Krucoff MW, Ohman EM, Steg PG, White H. Standardized Bleeding Definitions for Cardiovascular Clinical Trials: A Consensus Report From the Bleeding Academic Research Consortium.

Circulation. 2011;123:2736-2747.

9. Thygesen K, Alpert JS, Jaffe AS, Simoons ML, Chaitman BR, White HD, Writing Group on the Joint ESC/ACCF/AHA/WHF Task Force for the Universal Definition of Myocardial Infarction, Thygesen K, Alpert JS, White HD, Jaffe AS, Katus HA, Apple FS, Lindahl B, Morrow DA, Chaitman BA, Clemmensen PM, Johanson P, Hod H, Underwood R, Bax JJ, Bonow RO, Pinto F, Gibbons RJ, Fox KA, Atar D, Newby LK, Galvani M, Hamm CW, Uretsky BF, Steg PG, Wijns W, Bassand J$P$, Menasché $P$, Ravkilde J, Ohman EM, Antman EM, Wallentin LC, Armstrong PW, Simoons ML, Januzzi JL, Nieminen MS, Gheorghiade M, Filippatos G, Luepker RV, Fortmann SP, Rosamond WD, Levy D, Wood D, Smith SC, Hu D, Lopez-Sendon J-L, Robertson RM, Weaver D, Tendera M, Bove AA, Parkhomenko AN, Vasilieva EJ, Mendis S, ESC Committee for Practice Guidelines (CPG). Third universal definition of myocardial infarction. Eur Heart J. 2012;33:2551-2567.

10. Cutlip DE, Windecker S, Mehran R, Boam A, Cohen DJ, Es G-A van, Steg PG, Morel M, Mauri L, Vranckx P, McFadden E, Lansky A, Hamon M, Krucoff MW, Serruys PW. Clinical End Points in Coronary Stent Trials: A Case for Standardized Definitions. Circulation. 2007;115:23442351.

11. Kang L, Chen W, Petrick NA, Gallas BD. Comparing two correlated C indices with rightcensored survival outcome: a one-shot nonparametric approach. Stat Med. 2015;34:685-703.

12. Steyerberg EW, Pencina MJ, Lingsma HF, Kattan MW, Vickers AJ, Van Calster B. Assessing the incremental value of diagnostic and prognostic markers: a review and illustration. Eur J Clin Invest. 2012;42:216-228.

13. Pencina MJ, D'Agostino RB, D'Agostino RB, Vasan RS. Evaluating the added predictive ability of a new marker: from area under the ROC curve to reclassification and beyond. Stat Med. 2008;27:157-172; discussion 207-212.

14. Pencina MJ, D’Agostino RB, Pencina KM, Janssens ACJW, Greenland P. Interpreting incremental value of markers added to risk prediction models. Am J Epidemiol. 2012;176:473-481.

15. Gargiulo G, Valgimigli M, Capodanno D, Bittl JA. State of the art: duration of dual antiplatelet therapy after percutaneous coronary intervention and coronary stent implantation past, present and future perspectives. Eurolntervention J Eur Collab Work Group Interv Cardiol Eur Soc Cardiol. 2017;13:717-733.

16. Guerrero C, Garay A, Ariza-Solé A, Formiga F, Raposeiras-Roubín S, Abu-Assi E, D’Ascenzo F, Kinnaird T, Manzano-Fernández S, Alegre O, Sánchez-Salado JC, Lorente V, Templin C, Velicki L, Xanthopoulou I, Cerrato E, Rognoni A, Boccuzzi G, Omedè P, Montabone A, Taha S, Durante A, Gili S, Magnani G, Conrotto F, Bertaina M, Autelli M, Grosso A, Blanco PF, Quadri G, Varbella F, Tomassini F, Queija BC, Paz RC, Fernández MC, Pousa IM, Gallo D, Morbiducci U, Dominguez-Rodriguez A, Valdés M, Alexopoulos D, Iñiguez-Romo A, Gaita F, Cequier Á. Anemia in patients with acute coronary syndromes treated with prasugrel or ticagrelor: Insights from the RENAMI registry. Thromb Res. 2018;167:142-148. 
17. Amin AP, Bachuwar A, Reid KJ, Chhatriwalla AK, Salisbury AC, Yeh RW, Kosiborod M, Wang TY, Alexander KP, Gosch K, Cohen DJ, Spertus JA, Bach RG. Nuisance bleeding with prolonged dual antiplatelet therapy after acute myocardial infarction and its impact on health status. J Am Coll Cardiol. 2013;61:2130-2138.

18. Généreux P, Giustino G, Witzenbichler B, Weisz G, Stuckey TD, Rinaldi MJ, Neumann F-J, Metzger DC, Henry TD, Cox DA, Duffy PL, Mazzaferri E, Yadav M, Francese DP, Palmerini T, Kirtane AJ, Litherland C, Mehran R, Stone GW. Incidence, Predictors, and Impact of PostDischarge Bleeding After Percutaneous Coronary Intervention. J Am Coll Cardiol. 2015;66:10361045.

19. Almendro-Delia M, García-Alcántara Á, de la Torre-Prados MV, Reina-Toral A, ArboledaSánchez JA, Butrón-Calderón M, García-Guerrero A, de la Chica-Ruiz Ruano R, Hidalgo-Urbano R, García-Rubira JC. Safety and Efficacy of Prasugrel and Ticagrelor in Acute Coronary Syndrome. Results of a "Real World" Multicenter Registry. Rev Espanola Cardiol Engl Ed. 2017;70:952-959.

20. Abu-Assi E, Raposeiras-Roubin S, Cobas-Paz R, Caneiro-Queija B, Martínez-Reglero C, Rodríguez-Rodríguez JM, Baz A, Íñiguez-Romo A. Assessing the performance of the PRECISEDAPT and PARIS risk scores for predicting one-year out-of-hospital bleeding in acute coronary syndrome patients. Eurolntervention J Eur Collab Work Group Interv Cardiol Eur Soc Cardiol. 2018;13:1914-1922.

21. Raposeiras-Roubín S, Caneiro Queija B, D'Ascenzo F, Kinnaird T, Ariza-Solé A, ManzanoFernández S, Templin C, Velicki L, Xanthopoulou I, Cerrato E, Quadri G, Rognoni A, Boccuzzi G, Montabone A, Taha S, Durante A, Gili S, Magnani G, Autelli M, Grosso A, Flores Blanco P, Garay A, Varbella F, Tomassini F, Cobas Paz R, Cespón Fernández M, Muñoz Pousa I, Gallo D, Morbiducci U, Domínguez-Rodríguez A, Baz-Alonso JA, Calvo-Iglesias F, Valdés M, Cequier Á, Gaita F, Alexopoulos D, İñiguez-Romo A, Abu-Assi E. Usefulness of the PARIS Score to Evaluate the Ischemic-hemorrhagic Net Benefit With Ticagrelor and Prasugrel After an Acute Coronary Syndrome. Rev Esp Cardiol (Engl Ed). 2019; 72:215-223.

22. Ariza-Solé A, Formiga F, Lorente V, Sánchez-Salado JC, Sánchez-Elvira G, Roura G, Sánchez-Prieto R, Vila M, Moliner P, Cequier A. Efficacy of bleeding risk scores in elderly patients with acute coronary syndromes. Rev Esp Cardiol (Engl Ed). 2014;67:463-70. 


\section{SUPPLEMENTARY APPENDIX}

\section{Supplementary Methods \\ Leading Study Centers}

Dipartimento di Scienze Mediche, Divisione di Cardiologia, Città della Salute e della Scienza, Turin, Italy

Department of Cardiology, University Hospital Álvaro Cunqueiro, Vigo, Spain.

PolitoBIOMed Lab, Department of Mechanical and Aerospace Engineering, Politecnico di Torino.

\section{Participating Study Centers}

Department of Cardiology, Department of Medical Sciences, University of Torino, Italy.

Department of Cardiology, University Hospital Álvaro Cunqueiro, Vigo, Spain.

Cardiology Department, University Hospital of Wales, Cardiff, United Kingdom.

Department of Cardiology, University Hospital de Bellvitge, Barcelona, Spain.

Department of Cardiology, University Hospital Virgen Arrtixaca, Murcia, Spain.

Department of Cardiology, University Heart Center, University Hospital Zurich, Switzerland.

Institute of cardiovascular Diseases, Vojvodina, Serbia.

University Patras Hospital, Athens, Greece.

Interventional Unit, San Luigi Gonzaga University Hospital, Orbassano and Infermi Hospital, Rivoli, Italy.

Catheterization Laboratory, Maggiore della Carità Hospital, Novara, Italy.

Department of Cardiology, S.G. Bosco Hospital, Torino, Italy.

Department of Cardiology, Faculty of Medicine, Assiut University.

U.O. Cardiologia, Ospedale Valduce, Como, Italy. Department of Cardiology, University Hospital from Canarias, Tenerife, Spain. 


\section{SUPPLEMENTARY TABLES}

Supplementary table 1: variables comprising the PARIS bleeding risk score.

\begin{tabular}{|l|c|}
\hline Variable & Assigned points \\
\hline Age, years & 0 \\
$<50$ & 1 \\
$50-59$ & 2 \\
$60-69$ & 3 \\
$70-79$ & 4 \\
$\geq 80$ & 2 \\
\hline Body mass index, $\mathrm{kg} / \mathrm{m}^{2}$ & 0 \\
$<25$ & 2 \\
$25-34.9$ & 2 \\
$\geq 35$ & 0 \\
\hline Current smoking & 3 \\
Yes & 0 \\
No & 2 \\
\hline Anaemia & 0 \\
Present & \\
Absent & 2 \\
\hline Creatinine clearance $<60 \mathrm{ml} / \mathrm{min}$ & 0 \\
Present & \\
Absent & \\
\hline Triple therapy on discharge & 2 \\
Yes & \\
No & 2 \\
\hline
\end{tabular}


Supplementary table 2: variables comprising the PARIS ischemic risk score.

\begin{tabular}{|l|c|}
\hline Variable & Assigned points \\
\hline Diabetes mellitus & 0 \\
None & 1 \\
Non insulin-dependent & 3 \\
Insulin-dependent & \\
\hline ACS & 0 \\
No & 1 \\
Yes Tn-negative & 2 \\
Yes Tn-positive & 1 \\
\hline Current smoking & 0 \\
Yes & 2 \\
No & 0 \\
\hline Prior PCl & \\
Yes & 2 \\
No & 0 \\
\hline Prior CABG & \\
Yes & 2 \\
No & 0 \\
\hline Creatinine clearance $<60 \mathrm{ml} / \mathrm{min}$ & \\
Present & \\
Absent & \\
\hline
\end{tabular}


Supplementary Table 3. Net benefit of using the PRECISE-DAPT and PARIS scores compared to alternative strategies for identifying BARC type 3 or 5 bleeding risk conditional on different risk thresholds.

\begin{tabular}{|c|c|c|c|c|}
\hline $\begin{array}{c}\text { Risk } \\
\text { threshold }\end{array}$ & $\begin{array}{c}\text { Net benefit of assuming } \\
\text { all as low risk }\end{array}$ & $\begin{array}{c}\text { Net benefit of assuming } \\
\text { all as high risk }\end{array}$ & $\begin{array}{c}\text { Net benefit of using } \\
\text { PRECISE-DAPT }\end{array}$ & using PARIS \\
\hline $\mathbf{1}$ & $0 \%$ & $0,9 \%$ & $0,9 \%$ & $0,9 \%$ \\
\hline $\mathbf{2}$ & $0 \%$ & $-0,09 \%$ & $0,38 \%$ & $0,25 \%$ \\
\hline $\mathbf{3}$ & $0 \%$ & $-1,07 \%$ & $0,08 \%$ & $0 \%$ \\
\hline
\end{tabular}

Note: net benefit at different risk thresholds is calculated as \{true-positive classifications - [\% risk threshold/(100 - \% risk threshold $) \times$ false-positive classifications]\}/total number of participants.

The number of additional true positives per 100 patients the risk scores can identify without additional false positives, is calculated as follows: (\% net benefit of using the score of interest - \% net benefit of the alternative strategy in question)/[\% risk threshold/100 - risk threshold]). This value is the equivalent to the reduction in false positive without a decrease in the number of true positives. The calculated net benefits are relative to not use any risk score. 


\section{Class of risk of patients in the RENAMI registry}

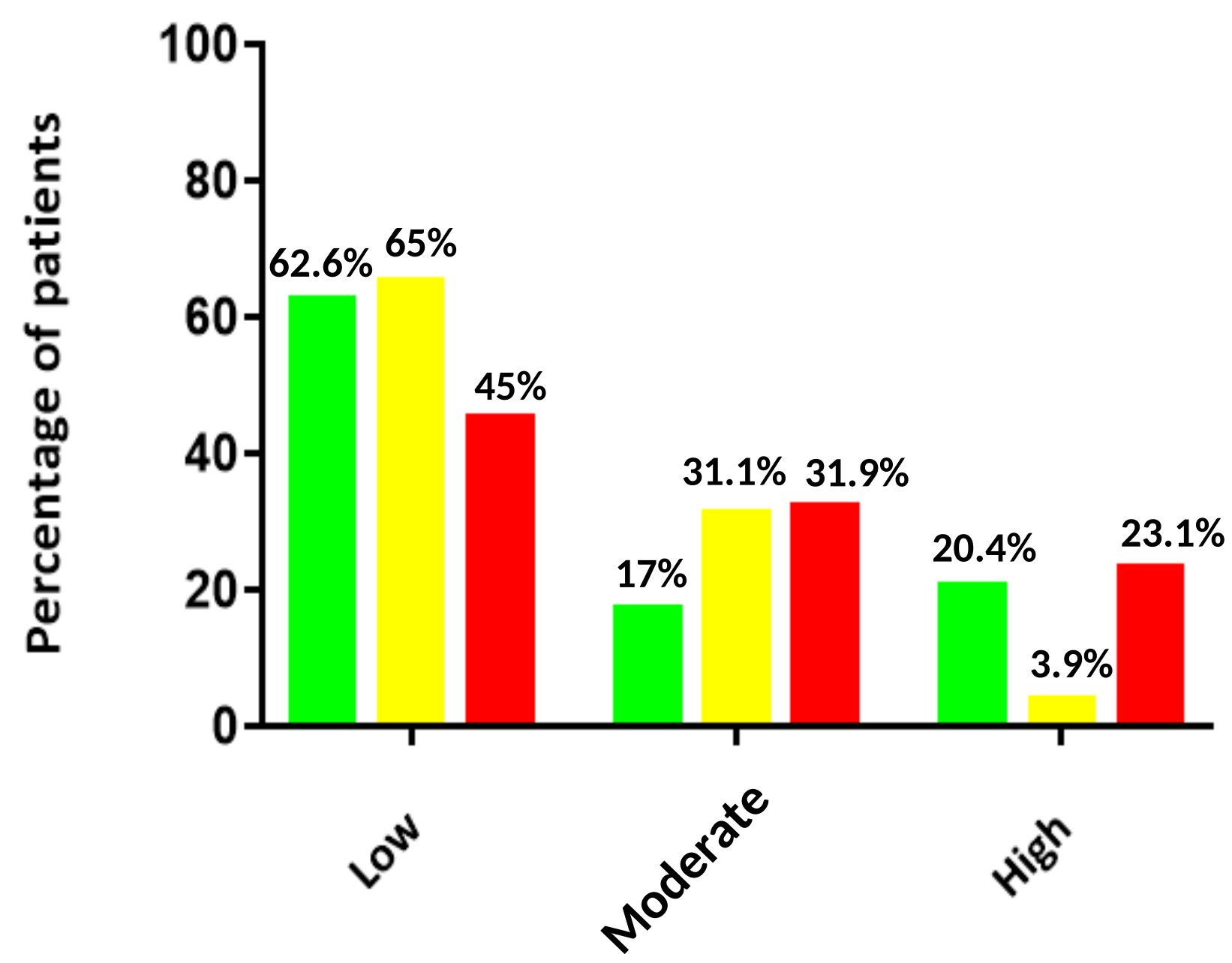

Figure 1. Patients risk class in the RENAMI registry using the PRECISEDAPT, PARIS bleeding and PARIS ischemic risk scores. 


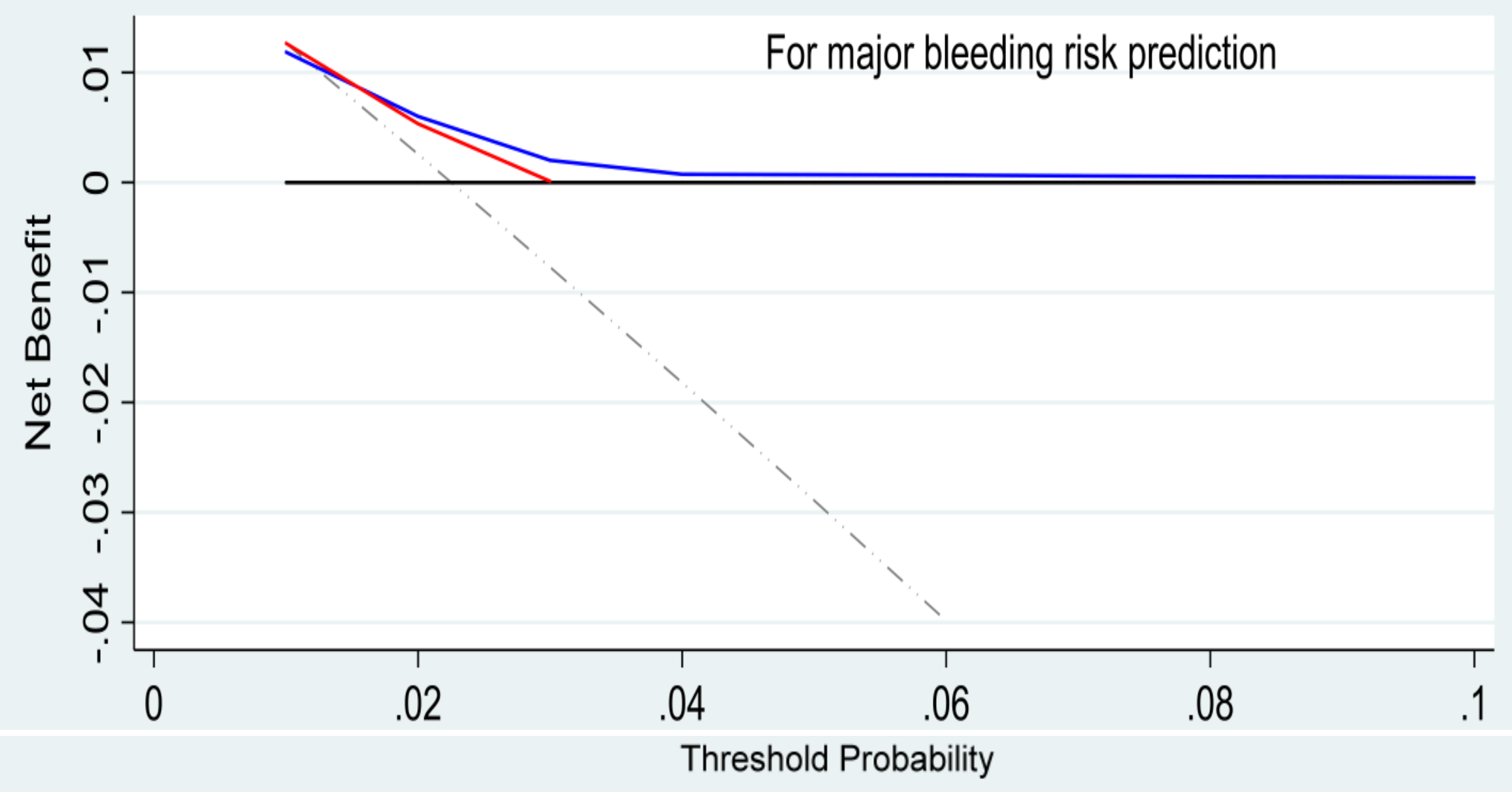

Treat all as if they are at high risk of bleeding

Treakill

PARTS BTTeeding

RS

Figure 4: Decision curves for the PRECISE DAPT and PARIS bleeding RS derived risk thresholds for predicting MB bleeding. 


\begin{tabular}{|c|c|c|c|}
\hline & RENAMI & $\begin{array}{c}\text { PRECISE-DAPT } \\
\text { (derivation cohort) }\end{array}$ & $\begin{array}{c}\text { PARIS (derivation } \\
\text { cohort) }\end{array}$ \\
\hline Number of patients & 4424 & 14963 & 4190 \\
\hline Age (mean \pm SD) & $60.9 \pm 11.5$ & $--^{*}$ & $63.6 \pm 11.0$ \\
\hline Age (median (IQR)) & $61.0(53-69)$ & $65.0(56.9-73)$ & $--^{*}$ \\
\hline Female, \% & 20.8 & 29.5 & 25.4 \\
\hline Weight, Kg & $80.1 \pm 13.8$ & $74.0(65-84)$ & $--^{*}$ \\
\hline $\mathrm{BMI}($ mean $\pm \mathrm{SD})$ & $27.4 \pm 4.1$ & $--^{*}$ & $29.3 \pm 5.5$ \\
\hline BMI median (IQR)) & $27(25.0-29.0)$ & $--^{*}$ & $--^{*}$ \\
\hline Active smoking, $\%$ & 29.1 & 28 & 17.8 \\
\hline Hypertension (\%) & 54 & 71.9 & 81.4 \\
\hline Diabetes Mellitus (\%) & 29.9 & 27.8 & 34.1 \\
\hline LVEF (mean \pm SD) & $51.2 \pm 9.4$ & $--^{*}$ & $--^{*}$ \\
\hline Peripheral vascular disease,\% & 3.6 & 10.4 & 8 \\
\hline Prior MI,\% & 16.5 & 19.8 & 24.9 \\
\hline Prior $\mathrm{PCl}, \%$ & 17.9 & $--^{*}$ & 41.9 \\
\hline Prior CABG,\% & 0.9 & $--^{*}$ & 14.4 \\
\hline Prior stroke,\% & 5.2 & 3.6 & 3.5 \\
\hline Prior Bleeding,\% & 2.4 & 1.9 & $--^{*}$ \\
\hline Malignancy,\% & 4.5 & $--^{*}$ & $--^{*}$ \\
\hline UA,\% & 9 & 22.7 & 29.9 \\
\hline NSTEMI,\% & 33 & 14 & 7.9 \\
\hline STEMI,\% & 58 & 18.9 & $--^{*}$ \\
\hline Haemoglobin (mean \pm SD) & $14.1 \pm 1.3$ & & $--^{*}$ \\
\hline Haemoglobin (median (IQR)) & $14(13.2-14.5)$ & $13.8(12.7-14.9)$ & $-^{*}$ \\
\hline Anaemia,\% & 1.9 & $--^{*}$ & 15 \\
\hline $\begin{array}{l}\text { WBC count }\left(10^{3} \text { units } / \mu \mathrm{L}\right) \\
(\text { mean } \pm S D)\end{array}$ & $10602 \pm 1381$ & $--{ }^{*}$ & $---*$ \\
\hline $\begin{array}{l}\text { WBC count }\left(10^{3} \text { units } / \mu \mathrm{L}\right) \\
\text { (median (IQR)) }\end{array}$ & $\begin{array}{c}10.600 \\
(8.200-12.335)\end{array}$ & $7.800(6.300-10.200)$ & ---* \\
\hline $\mathrm{CrCl}(\mathrm{mL} / \mathrm{min})($ mean $\pm \mathrm{SD})$ & $96.7 \pm 37.3$ & $79.1(60.8-98.0)$ & $--^{*}$ \\
\hline $\mathrm{CrCl}(\mathrm{mL} / \mathrm{min})$ (median (IQR)) & $93(71-118)$ & & \\
\hline $\mathrm{CrCl}<60 \mathrm{~mL} / \mathrm{min}, \%$ & 15.9 & & 17.8 \\
\hline DES,\% & 93 & 87.2 & 100 \\
\hline BMS,\% & 7 & 12.8 & 0 \\
\hline \multicolumn{4}{|l|}{ Treatment at discharge } \\
\hline Aspirin,\% & 99.9 & 98.7 & \\
\hline Clopidogrel,\% & 0 & 87.7 & 92.1 \\
\hline Prasugrel,\% & 39 & 7.6 & 6.2 \\
\hline Ticagrelor,\% & 61 & 3.9 & 0 \\
\hline Statin,\% & 51 & 89.4 & \\
\hline ACE inhibitors/ARB II,\% & 34 & 66.7 & \\
\hline B-blocker,\% & 37 & 74.3 & \\
\hline
\end{tabular}

Table 1: Baseline characteristics. $\mathrm{LVEF}=$ left ventricle ejection fraction. $\mathrm{MI}=$ myocardial infarction. $\mathrm{PCl}=$ percutaneous coronary intervention. $\mathrm{CABG}=$ coronary artery bypass graft. $\mathrm{UA}=$ unstable angina. $\mathrm{NSTEMI}=$ 
non-ST segment elevated myocardial infarction. STEMI= ST segment elevated myocardial infarction. ACE/ARB: ACE inhibitor or angiotensin-II receptor blocker. * Data not reported in the original study. 


\begin{tabular}{|c|c|c|}
\hline \multicolumn{3}{|c|}{ Discrimination capacity (C-statistic) for MB risk prediction by different DAPT durations } \\
\hline & PRECISE DAPT & PARIS bleeding RS \\
\hline Overall, $\mathrm{n}^{\circ}$ of $\mathrm{MB}$ events $=83$ & $0.653(0.591-0.714)$ & $0.593(0.528-0.658)$ \\
\hline 12 months, $\mathrm{n}^{\circ}$ of MB events $=44$ & $0.624(0.530-0.718)$ & $0.526(0.432-0.620)$ \\
\hline $\begin{array}{l}\text { More than } 12 \text { months, } n^{\circ} \text { of } \mathrm{MB} \\
\text { events= } 14\end{array}$ & $0.648(0.491-0.805)$ & $0.666(0.514-0.818)$ \\
\hline $\begin{array}{l}\text { Less than } 12 \text { months, } n^{\circ} \text { of } \mathrm{MB} \\
\text { events }=25\end{array}$ & $0.689(0.596-0.782)$ & $0.633(0.517-0.749)$ \\
\hline \multicolumn{3}{|c|}{ Discrimination capacity (C-statistic) for ischemic risk prediction by different DAPT durations } \\
\hline & PRECISE DAPT & PARIS ischemic RS \\
\hline Overall, $n^{\circ}$ of ischemic events $=133$ & $0.568(0.509-0.626)$ & $0.604(0.550-0.657)$ \\
\hline 12 months; $\mathrm{n}^{\circ}$ of ischemic events $=54$ & $0.525(0.423-0.628)$ & $0.571(0.492-0.650)$ \\
\hline $\begin{array}{l}\text { More than } 12 \text { months; } n^{\circ} \text { of ischemic } \\
\text { events }=40\end{array}$ & $0.537(0.431-0.643)$ & $0.656(0.564-0.755)$ \\
\hline $\begin{array}{l}\text { Less than } 12 \text { months } n^{\circ} \text { of ischemic } \\
\text { events }=39\end{array}$ & $0.648(0.550-0.745)$ & $0.597(0.492-0.702)$ \\
\hline \multicolumn{3}{|c|}{ Discrimination capacity (C-statistic) for MB risk prediction in STEMI patients } \\
\hline & PRECISE DAPT & PARIS bleeding RS \\
\hline $\mathrm{n}^{\circ}$ of MB events in STEMI: 48 & $0.632(0.547-0.717)$ & $0.575(0.487-0.663)$ \\
\hline \multicolumn{3}{|c|}{ Discrimination capacity (C-statistic) for ischemic risk prediction in STEMI patients } \\
\hline & PRECISE DAPT & PARIS ischemic RS \\
\hline $\mathrm{n}^{\circ}$ of ischemic events in STEMI: 70 & $0.574(0.488-0.659)$ & $0.629(0.558-0.701)$ \\
\hline \multicolumn{3}{|c|}{ Discrimination capacity (C-statistic) for MB risk prediction in NSTEACS patients } \\
\hline & PRECISE DAPT & PARIS bleeding RS \\
\hline $\mathrm{n}^{\circ}$ of MB events in NSTEACS: 35 & $0.682(0.597-0.767)$ & $0.619(0.524-0.713)$ \\
\hline \multicolumn{3}{|c|}{ Discrimination capacity (C-statistic) for ischemic risk prediction in NSTEACS patients } \\
\hline & PRECISE DAPT & PARIS ischemic RS \\
\hline $\mathrm{n}^{\circ}$ of ischemic events in NSTEACS: 63 & $0.551(0.473-0.628)$ & $0.569(0.489-0.650)$ \\
\hline \multicolumn{3}{|c|}{ Discrimination capacity (C-statistic) for MB risk prediction in prasugrel patients } \\
\hline & PRECISE DAPT & PARIS bleeding RS \\
\hline $\begin{array}{l}\mathrm{n}^{\circ} \text { of MB events in prasugrel treated } \\
\text { pts: } 25\end{array}$ & $0.623(.504-.743)$ & $0.586(0.460-0.713)$ \\
\hline \multicolumn{3}{|c|}{ Discrimination capacity (C-statistic) for ischemic risk prediction in prasugrel patients } \\
\hline & PRECISE DAPT & PARIS ischemic RS \\
\hline $\begin{array}{l}\mathrm{n}^{\circ} \text { of ischemic events in prasugrel } \\
\text { treated pts: } 49\end{array}$ & $0.525(0.429-0.620)$ & $0.639(0.551-0.727)$ \\
\hline \multicolumn{3}{|c|}{ Discrimination capacity (C-statistic) for MB risk prediction in ticagrelor patients } \\
\hline & PRECISE DAPT & PARIS bleeding RS \\
\hline $\begin{array}{l}\mathrm{n}^{\circ} \text { of } \mathrm{MB} \text { events in ticagrelor treated } \\
\text { pts: } 58\end{array}$ & $0.648(0.576-0.719)$ & $0.573(0.499-0.6488)$ \\
\hline \multicolumn{3}{|c|}{ Discrimination capacity (C-statistic) for ischemic risk prediction in ticagrelor patients } \\
\hline & PRECISE DAPT & PARIS ischemic RS \\
\hline $\begin{array}{l}\mathrm{n}^{\circ} \text { of ischemic events in ticagrelor } \\
\text { treated pts: } 84\end{array}$ & $0.585(0.514-0.657)$ & $0.574(0.505-0.642)$ \\
\hline \multicolumn{3}{|c|}{ Discrimination capacity (C-statistic) for MB risk prediction in patients $>75$ years } \\
\hline & PRECISE DAPT & PARIS bleeding RS \\
\hline $\begin{array}{l}\mathrm{n}^{\circ} \text { of } \mathrm{MB} \text { events in the } 581 \mathrm{pts}>75 \\
\text { years: } 21\end{array}$ & $0.621(0.559-0.691)$ & $0.603(0.547-0.663)$ \\
\hline
\end{tabular}




\begin{tabular}{|l|l|l|}
\hline & PRECISE DAPT & PARIS bleeding RS \\
\hline $\begin{array}{l}\mathrm{n}^{\circ} \text { of MB events in the } 261 \mathrm{pts} \text { with } \\
\text { serum creatinine }>1.5 \mathrm{mg} / \mathrm{dl}: 7\end{array}$ & $0.744(0.626-0.864)$ & $0.693(0.587-0.803)$ \\
\hline
\end{tabular}

Table 2: C-statistic analysis for RSs accuracy for different subgroups of patients. 
Prof. Valgimigli has received research grants to the institution from Terumo, Medicure, Abbott, Astrazeneca and honorarium fees from Abbott, Chiesi, Bayer, Daiichi Sankyo, Amgen, Terumo, Astrazeneca, Alvimedica and Biosensors.

None of the other authors have any conflict of interests to declare 


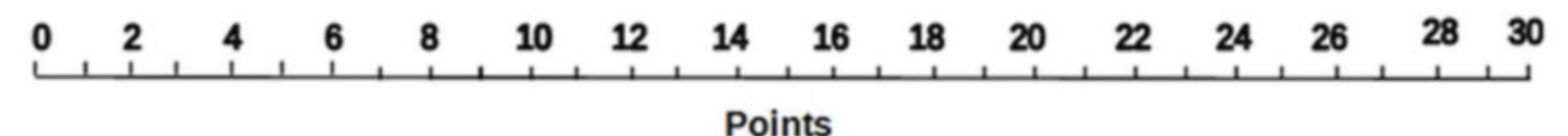

$\underbrace{\geq 12.0 \quad 11.0 \quad \leq 10.0}_{\text {Hemoglobin }(\mathrm{g} / \mathrm{dL}}$

\begin{tabular}{|c|c|c|c|c|c|c|c|}
\hline$\leq 5$ & 8 & 10 & 12 & 14 & 16 & 18 & $\geq 20$ \\
\hline
\end{tabular}
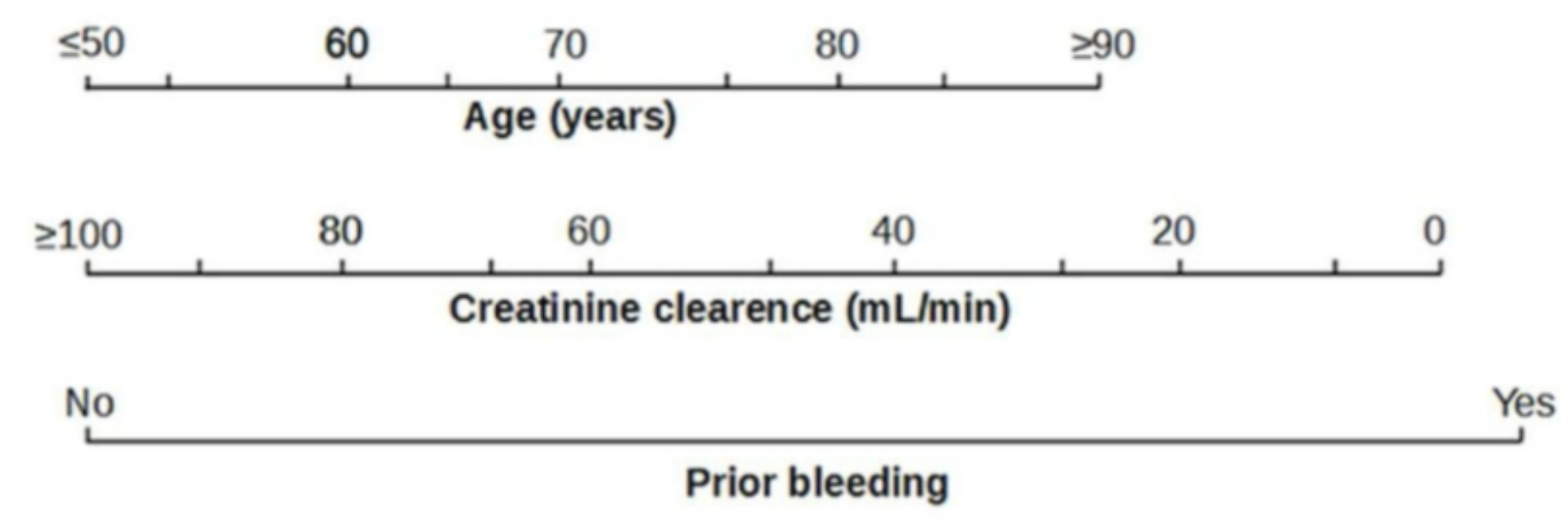

Supplementary materials figure 1: variables comprising the PRECISE-DAPT bleeding risk score. 

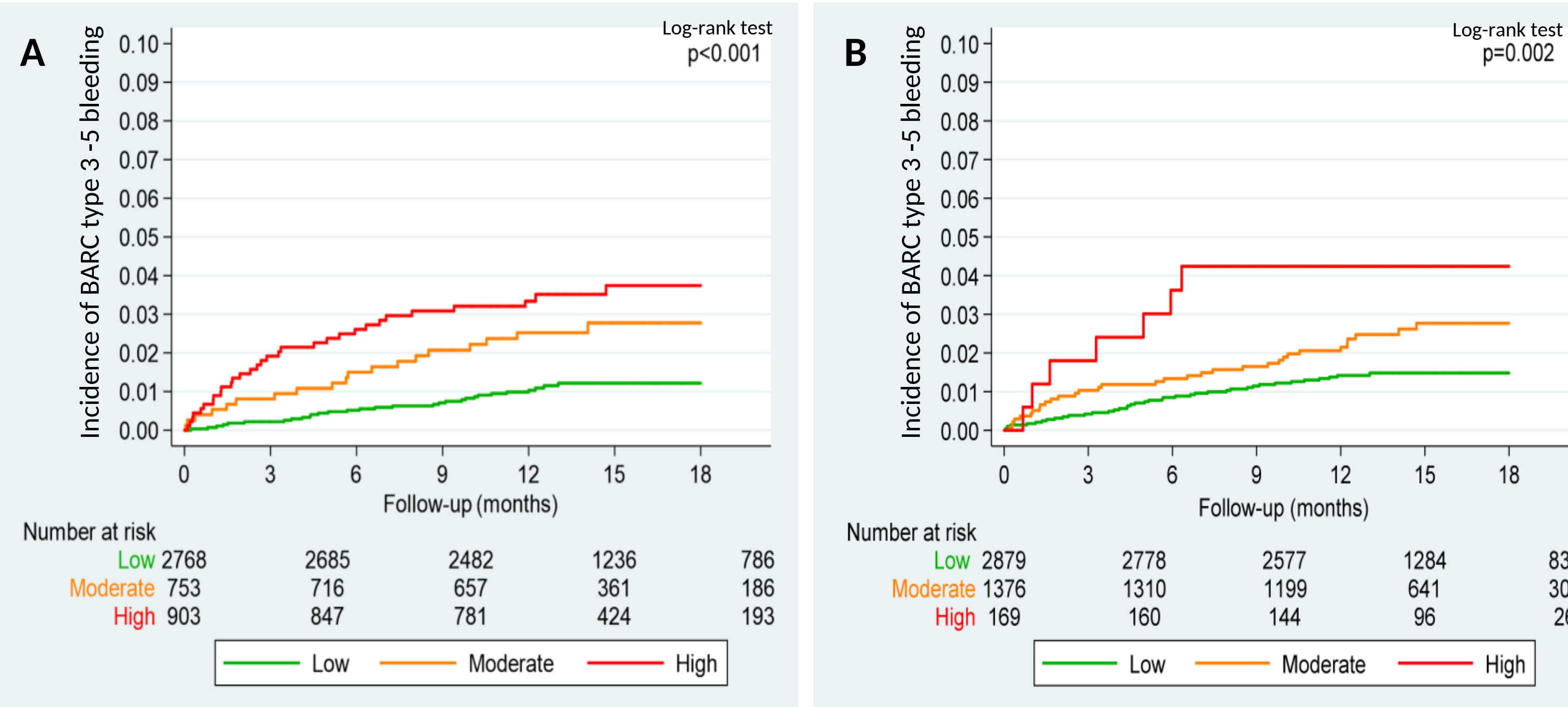

Supplementary Figure 2. Kaplan-Meier curves for BARC type 3 or 5 bleeding. A) Using PRECISE-DAPT classification system, and B) using PARIS bleeding risk classifcation system. 


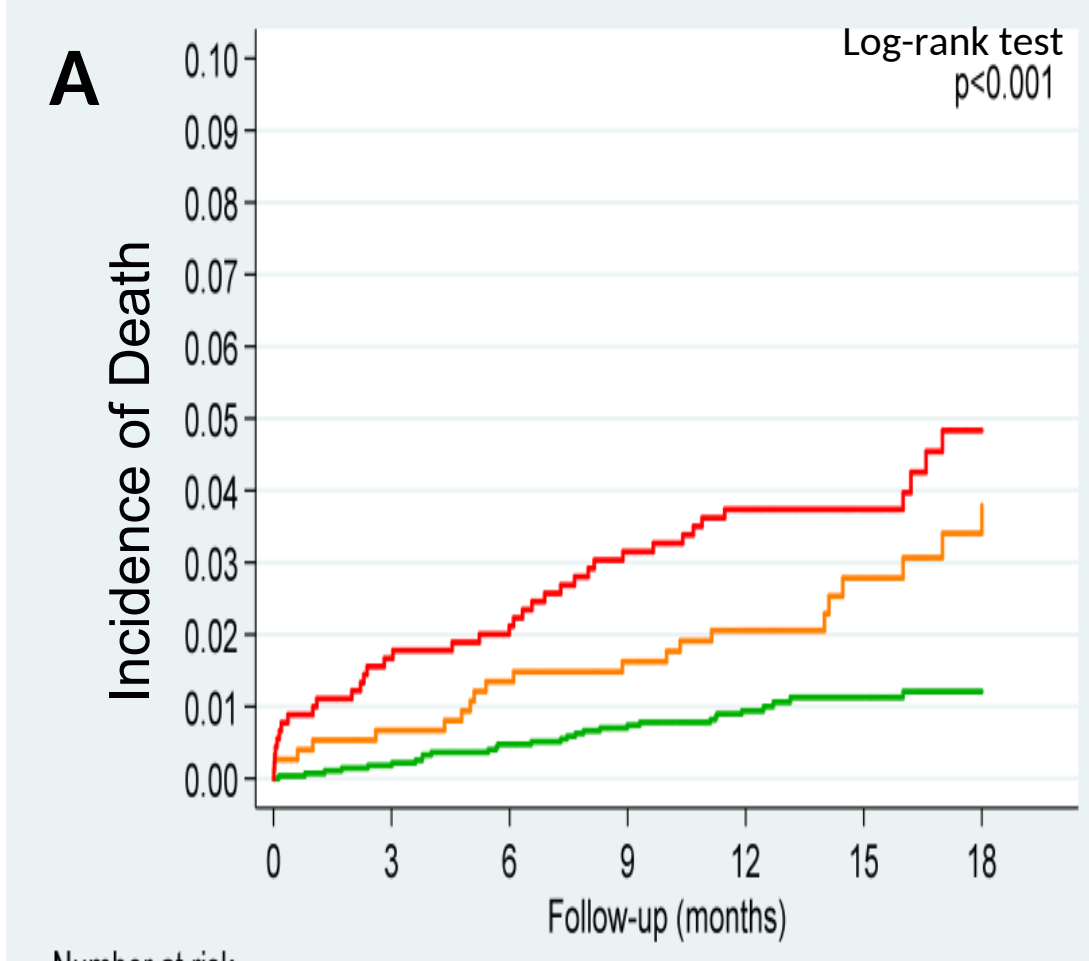

Number at risk

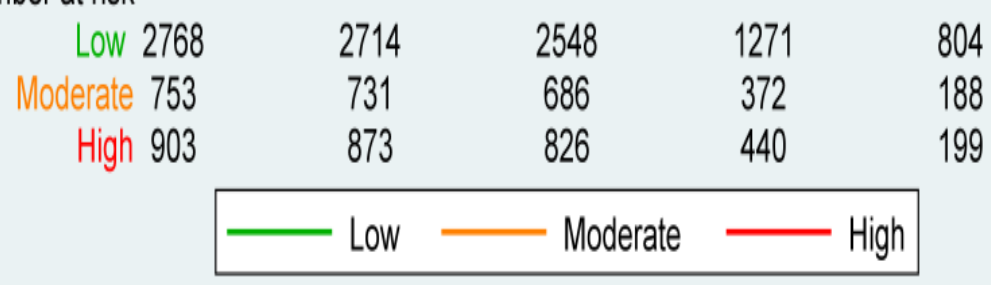

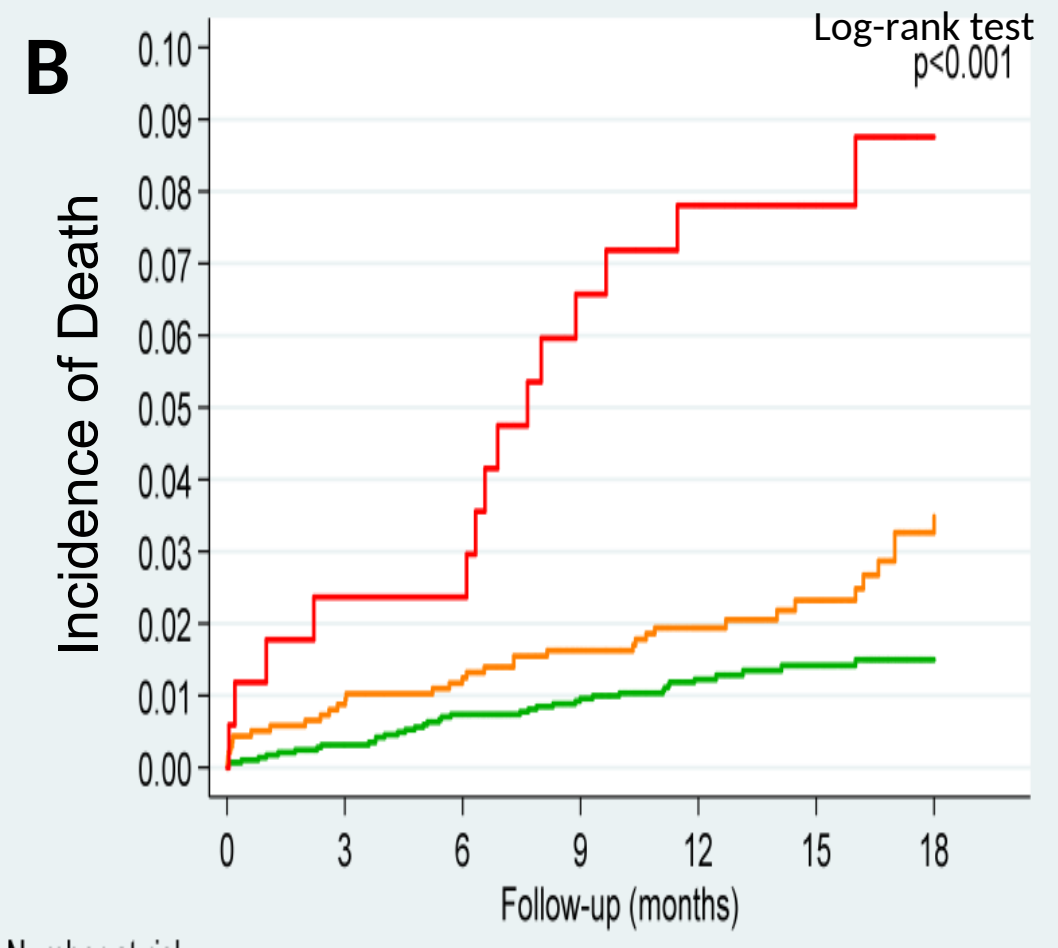

Number at risk

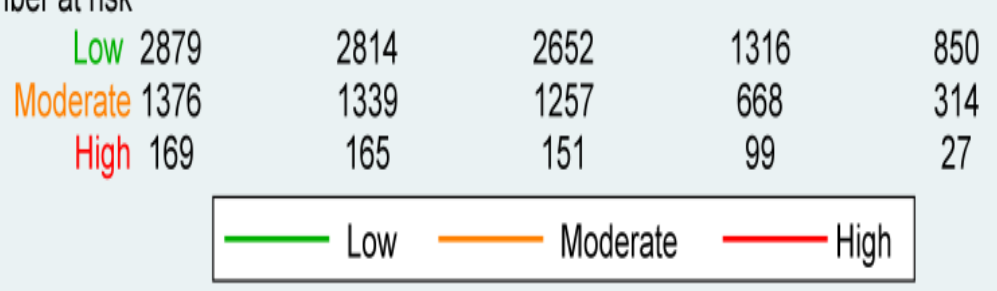

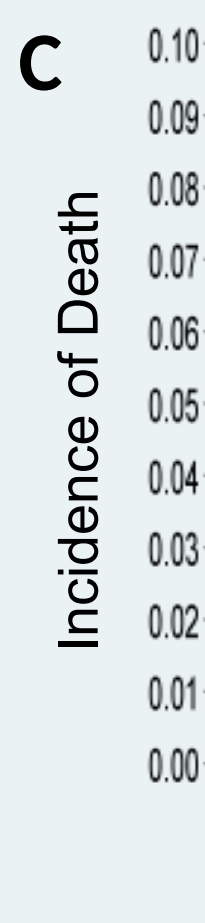

Number at risk

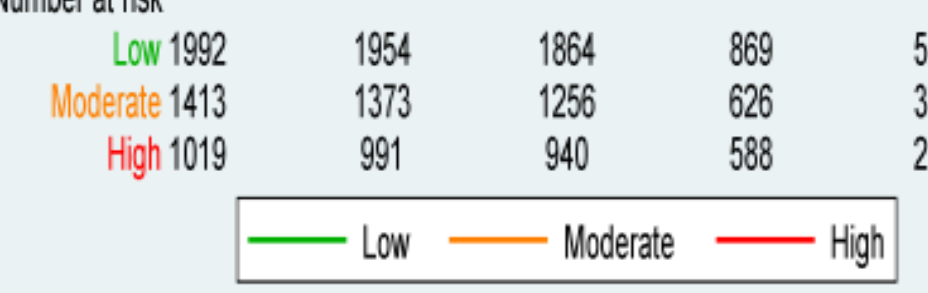

Supplementary materials figure 3. Kaplan-Meier curves for cardiovascular death. A) Using PRECISE-DAPT risk strata. B) Using PARIS bleeding RS risk strata. C) Using PARIS ischemic RS risk strata. 

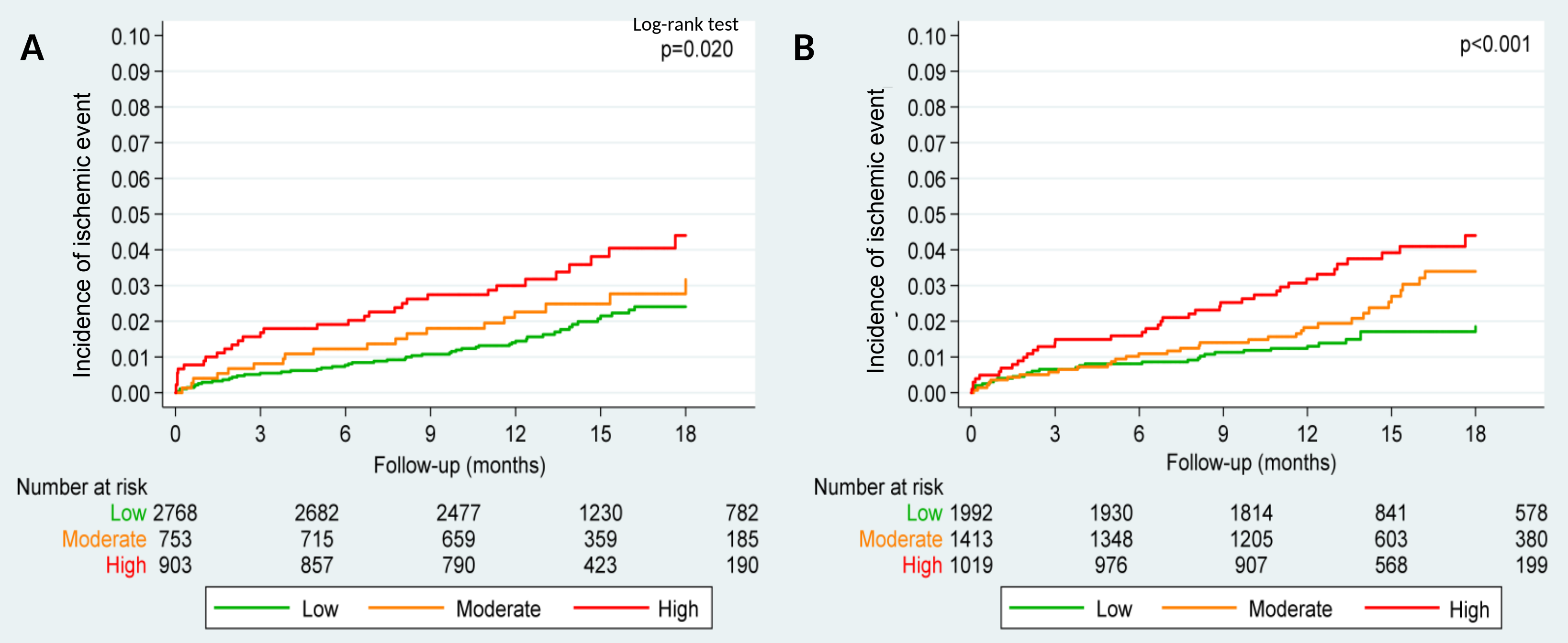

Supplementary materials figure 4. Kaplan-Meier curves for Myocardial infraction/stent thrombosis. A) Using PRECISE-DAPT risk strata. B) Using PARIS ischemic RS risk strata. 
